\title{
A CONSTRUÇÃO DO SILÊNCIO: UM ESTUDO DA OBRA POÉTICA DE ORIDES FONTELA
}

Alexandre Rodrigues da Costa*

RESUMO:

Este texto analisa a obra de Orides Fontela, mostrando como a poeta aborda o silêncio e a morte de forma bastante pessoal, $e$, às vezes, inusitada.

PALAVRAS-CHAVE: poesia, silêncio, nada, morte.

Nos poemas de Orides Fontela ${ }^{1}$ instaura-se uma busca. Busca pela palavra exata, pelo verso preciso, aquele que traduz a solidão que se coloca entre o sujeito e o mundo, entre a voz e o silêncio. Daí que essa busca descortine em sua obra uma estranha realidade, na qual as coisas surgem fragmentadas, reinterpretadas por um olhar que não quer isolá-las do mundo, mas, ao contrário, se fundir a elas e ao mundo. Em quase todos seus poemas, há uma clara negação da palavra em favor do silêncio, do nada, de maneira que, como afirma Antonio Candido, "os seus poemas partem da fixação com o nada, na tentativa de afirmar o ser, - que é o eu do poeta, mas, sobretudo, o poema realizado, atrás do qual ele se eclipsa" (Candido, 1983: 3). 0 ser afirmado pelo silêncio. Ou, conforme Marilena Chauí, uma "vigília lírica e irônica, que tem a força de um soco na boca do estômago mesclado ao esplendor do primeiro olhar" (Chauí, 1996: 9). Essa estranha declaração de Marilena Chauí talvez torne um pouco mais claro o que estamos tentando dizer aqui, ou seja, o fato de que a poesia de Orides Fontela tem uma dicção própria que, ao mesmo tempo em que estabelece um diálogo com tradições poéticas e filosóficas, traz para o cenário da poesia brasileira uma visão bem particular de mundo. E essa visão talvez seja o que mais chame a atenção.

* Mestre em Letras: Estudos Literários (Ārea de concentração: Teoria da Literatura), 2001. 


\section{EM TESE}

Belo Horizonte, v. 6, p. I-253, ago. 2003

Para aquele que escreve, o silêncio surge como desvio da meta programada. Para todo lado que se olhe, lá está ele, oferecendo a liberdade, a opção de não se arriscar no inferno paradisíaco que é a escrita. Ao encarar o silêncio, calamo-nos ou o transformarmos em fala. Mas esse transformar não implica o desaparecimento total do silêncio, pois para que a fala exista, ela precisa de pausas, daquilo que faça com que ela não seja um turbilhão de palavras, algo sem sentido. Dessa forma, o silêncio afirma sua presença na fala, ao apagar cada palavra, cada imagem, deixando um espaço aberto no qual algo logo se projetará. No entanto, esse é o silêncio visto a partir do entendimento comum. No poema, ele adquire um outro significado, talvez mais amplo, que coloca o sujeito frente à sua própria existência. Para Orides Fontela, a palavra cumpre sua existência a partir do silêncio que the define os limites, onde a insuficiência é sua própria matéria e a morte torna-se desejo de impessoalidade, fuga da consciência, ato de desumanização:

\section{FALA}

Tudo

será difícil de dizer:

a palavra real

nunca é suave.

Tudo será duro:

luz impiedosa

excessiva vivência

consciência demais do ser.

Tudo será

capaz de ferir. Será

agressivamente real.

Tão real que nos despedaça.

Não há piedade nos signos

e nem no amor: o ser

é excessivamente lúcido

e a palavra é densa e nos fere.

(Toda palavra é crueldade.) (Fontela, 1988: 31)

0 poema, do livro Transposição, se estrutura em três movimentos, que correspondem às três primeiras estrofes, respectivamente. A questão da fala ganha dentro desses movimentos um desenvolvimento particular, no qual a palavra é interpretada 
como aquilo que nos impede de escapar ao real e à consciência. Aberta sob as exigências de se cumprir como futuro, a palavra marca sua realidade pela negação da realidade. 0 presente não existe, já que a palavra é um contínuo fluir, através do qual a consciência ganha forma e tenta dar forma àquilo que a vive, o mundo aberto em feridas, a angústia de não podermos articular pela compreensão tudo que nos chega, organizar o quebra-cabeça definitivo, cujas peças se tornam a própria realidade. Mas nem mesmo a palavra verdadeira, que aqui podemos entender como palavra poética, consegue suplantar esse enigma, uma vez que ela se torna também enigma, no momento em que se fecha em signo de algo que não vive mais, em imagem de uma coisa que já foi esquecida pelo excesso de lucidez. Eis a sentença que o poema nos oferece: por sermos conscientes, vivemos sempre à sombra daquilo que nos escapa, cunhamos nas palavras as diferenças entre o que vemos e o que pensamos ver. Como sinal de humanidade, resta apenas aceitar que toda palavra é crueldade e que todo esquecimento é bem-vindo.

Mas não podemos ignorar que em Stéphane Mallarmé e em Rainer Maria Rilke o silêncio já é identificado com o nada. 0 nada que encontramos nas coisas, que nos oferece uma proximidade com a morte, como quer Rilke, ou o nada que Mallarmé vê como o absoluto, aquilo que está em oposição ao mundo do qual participamos, o do cotidiano reconhecível. Em Orides Fontela, essas duas poéticas se articulam: um pensamento que vê nas coisas um espaço arquitetado para a morte e outro que almeja através do poema ser uma contínua transposição. Nessas duas perspectivas, ao contrário da fala comum, o silêncio no poema não está em oposição às palavras, pois, conforme Maurice Blanchot:

no momento exato em que a linguagem nos cerca de uma ausência universal e nos livra da obsessão da presença do mundo, eis que o silêncio, para se expressar, apela para algo material, torna-se presente de uma maneira que arruína a orgulhosa construção erguida sobre o vazio, ela, a própria ausência, não tem outro recurso, para se introduzir no mundo dos valores significativos e abstratos, senão o de se realizar como uma coisa. (Blanchot, 1997: 43)

0 silêncio como coisa se realiza naquilo que José Guilherme Merquior chamou de poesia do pensamento, e que tem origem "quando Goethe acolheu em si a capacidade de reflexão ontológica que nenhum filósofo profissional alemão, entre Leibniz e a maturidade de Kant, soubera empregar" (Merquior, 1972: 22). Tal perspectiva 


\section{EM TESE}

Belo Horizonte, v. 6, p. I-253, ago. 2003

aparece em Mallarmé na forma de uma poesia da poesia, que não se limita a uma simples meditação sobre a criação literária, mas "é a encarnação de uma teoria do ser em geral; o exame da criação é uma ontologia". No entanto, é bom ressaltar que isso não significa, conforme José Guilherme Merquior, rejeição do mundo, pois Mallarmé "pretendia, ao contrário, descobrir na imanência a cintilação multiforme do significado e do ser" (Merquior, 1972: 24). Ora, é exatamente neste ponto que a poesia de Rilke - resguardadas suas particularidades - encontra confluências com a de Mallarmé, pois a poesia que se detém sobre as coisas, aquela que abandona o subjetivismo, a exaltação do eu, para abraçar o objetivismo na sua forma mais pura, tende a fazer do espaço do poema a construção consciente do próprio pensar.

Também para Orides Fontela o poema se torna espaço de reflexão tanto do fazer poético quanto da investigação ontológica. Em vez de o poema buscar representar estados de ânimo, estabelece-se a noção de que o pensamento, a filosofia, também é algo cabível de ser representado, de maneira que razão e sentimento não estão em oposição, mas são constituintes de um mesmo processo:

As palavras refletem-se mutuamente; e antes mesmo de haver, no poema, a imitação de uma situação qualquer, realiza-se uma como que mímese interna, que não é senão o sistema das correspondências entre os vários elementos do significante. A maior ou menor energia da mímese interna - e não a ocorrência maior ou menor de conteúdos intelectuais no poema - determina o grau de realização estética do discurso lírico. (Merquior, 1972: 21)

Esse grau de correspondência é alcançado por Orides Fontela através da identidade que ela vê entre a poesia e a filosofia, pois para a poeta "poesia não é loucura nem ficção, mas sim um instrumento altamente válido para apreender o real" (Fontela, 1998: 13). Nesse sentido, seu ideal de poesia "acolhe o irracional, 0 sonho, inventa e inaugura os campos do real, canta" (Fontela, 1998: 13). Percebemos que nas duas citações, Orides Fontela acentua o caráter do real como um dos pontos determinantes de sua poética. A presença da filosofia em sua obra nasce de uma necessidade de expor esse real, de expressar como a transitoriedade afirma nosso espaço no mundo, "o contato esquivo e rebelde entre o ser e o poema na revelação da linguagem" (Merquior, 1972: 39). A objetividade e a lucidez tornam-se, assim, partes de um esforço para se alcançar o indefinível, aquilo que constitui o processo poético entre a estrutura e o acaso e que "reflete a natureza aberta do ser, a sua 
intimidade com o nada, a sua manifestação escandida entre a configuração e a dissolução, entre o desenho na areia e a água que o desfaz" (Merquior, 1972: 23).

Mas a preocupação com a existência em Orides Fontela não se limita apenas à esfera da filosofia, pois como a própria poeta disse: "poesia, filosofia, zen e o mais que vier, tudo serve - ruma ao não-dito, ao nunca dito, ao inexprimível" (Fontela, 1998: 15). Talvez, por isso, o silêncio se fixe em sua obra não simplesmente como tentativa de alcançar o transcendental, mas gesticule uma consciência que tenta abarcar a vida em sua totalidade. Pois apesar do cotidiano não ser visto em seus poemas sob o prisma do comprometimento social, nem se deter em momentos determinados da história, em sua obra percebe-se um olhar que busca, nas coisas, apreender seus instantes, capturar o presente para projetar o eu na estranha matéria que compõe o mundo:

$$
\begin{aligned}
& \text { Alta agonia é ser, difícil prova: } \\
& \text { entre metamorfoses superar-se } \\
& \text { e - essência viva em pureza suprema - } \\
& \text { despir os sortilégios, brumas, mitos. }
\end{aligned}
$$

Alta agonia é esta raiz, pureza de contingência extrema a abeberar-se nos mares do Ser pleno e, arrebatada, fazer-se única em seu lúcido fruto.

Alta agonia é ser: essencial tarefa humana e sobre-humana graça de renascermos em solidão vera

e em solidão - dor suportada e glória em nossa contingência suportamos

0 peso essencial do amor profundo. (Fontela, 1988: 244)

0 poema, sem título, pertencente à seção "Antigos", do livro Rosácea, é considerado pela poeta como uma espécie de programa de vida, que, em suas palavras, "não renego nunca e nem jamais conseguirei cumprir, porém é minha tarefa tentar" (Fontela, 1998:13). A repetição da expressão "alta agonia" nas três primeiras estrofes do soneto assume aqui esse sentido mesmo de litania, de glória que surge da dor, da agonia, da solidão. Por isso, o poema se traduz também como aceitação da morte, uma vez que a meta maior é suportar "o peso essencial do amor profundo". Amor 


\section{EM TESE}

Belo Horizonte, v. 6, p. I-253, ago. 2003

que dilui as fronteiras entre os seres através da contingência e afirma a vida em seu presente:

Só no ato do amor - pela límpida abstração de estrela do que se sente capta-se a incógnita do instante que é duramente cristalina e vibrante no ar e a vida é esse instante incontável, maior que o acontecimento em si: no amor 0 instante de impessoal jóia refulge no ar, glória estranha de corpo, matéria sensibilizada pelo arrepio dos instantes. (Lispector, 1973: 10)

0 belo texto de Clarice Lispector aqui não nos serve simplesmente como adorno, mas para demonstrar que a poesia de Orides Fontela almeja, com seus versos curtos e sua linguagem precisa, alcançar esse instante impessoal, no qual a vida, ao ser fonte de sofrimento, é uma forma de liberdade. Liberdade como projeto para a morte, como um acontecer que se realiza ininterruptamente, espelhado na palavra, à mercê do impossível.

Quando começamos a ler os poemas de Orides Fontela, a tendência que temos é a de captar, sintetizar, sua poética. Enfim, encontrar um sentido que perpassasse por toda sua obra. Não encontramos apenas um, mas vários, junto a uma riqueza e a uma beleza que nos surpreendem. No entanto, o poema como enigma, linguagem que ao voltar para si mesma faz do silêncio sua gramática, aponta, na obra de Orides Fontela, também para morte. E a partir da morte, percebemos que a obra de Orides Fontela é mais do que metalinguagem e reflexão ontológica. É poesia, e como toda poesia, se sustenta, à beira do abismo, de si mesma. E o que isso vem a significar? Que, assim como Sêneca soube expressar um dos sentidos da vida, "devese aprender a viver por toda a vida e, por mais que tu talvez te espantes, a vida toda é um aprender a morrer" (Sêneca, 1993: 34). Assim, talvez poderíamos encarar a literatura: deve-se aprender a escrever por toda a vida e, por mais que tu talvez te espantes, escrever é um aprender a morrer.

Se o silêncio na obra de Orides Fontela faz parte do tecido da trama verbal, dando forma às palavras e ao universo que se abre a partir delas, o espaço entre a poeta e os objetos pertencentes ao cotidiano fundamenta-se como um lugar de comunhão, que logo a palavra interromperá, pois é ela que impede o abandono definitivo, a abertura para o mundo, para o estado de coisa. Por isso, a palavra precisa ser vista como "orgulhosa construção erguida sobre o vazio" (Blanchot, 1997:43), na qual a ausência "não tem outro recurso, para se introduzir no mundo dos 
valores significativos e abstratos, senão o de se realizar como uma coisa" (Blanchot, 1997:43), silêncio que se torna lucidez.

Toda sucessão de imagens em Orides carrega fragmentações que são como fissuras da linguagem. Nesse sentido, apenas a razão pode reorganizar, interferir, num processo que tem como motriz o mundo espelhado em fragmentos, a realidade vista através da ausência instaurada em imagem, em palavra. Como diz Marco Lucchesi, "entre o conceito e sua sombra emerge o vazio sobre o qual se sustenta a imagem, de quanto não se pode arrostar: a plenitude na falta" (Lucchesi, 1998: 97). 0 silêncio que surge daí se completa com o sentido de identidade que a ausência da face oferece, mas isto não quer dizer que haja uma anulação de quem escreve, pois a poesia que tenta entender a realidade acaba, de certa forma, sempre sendo " 'alta agonia' e 'dificil prova' que devemos tentar para realizar nossa humanidade" (Fontela, 1998: 13). A lucidez, ao mesmo tempo em que cria um sentido de posse sobre o que não pode ser visto, inaugura um gesto em que a descoberta do mundo abre-se na impossibilidade da compreensão total, em que o conceito de beleza, antes de ser subliminar, é o atrito do próprio sujeito com sua ausência.

Dessa forma, a poesia de Orides Fontela se utiliza da palavra como uma espécie de projeto para a morte e para a vida, no qual o poético surge do estranhamento em que colocamos o mundo, quando as coisas são vistas como se a fosse a primeira vez, quando o olhar não quer ser a perfeição de cada coisa em seu último abrigo, mas, ao contrário, expõe a fragilidade com que nos movemos no mundo e fazemos de nosso rastro o grande silêncio. 


\section{EM TESE}

Belo Horizonte, v. 6, p. I-253, ago. 2003

NOTA:

1. Orides de Lourdes Teixeira Fontela nasceu em São João da Boa Vista, SP, em 21 de abril de 1940. Filha de um operário e de uma dona de casa, começou a escrever ainda criança, sendo que, com o passar dos anos, ganhou fama em sua terra a ponto de adquirir aura de poeta municipal. Seu interesse pela filosofia levou-a à USP, onde concluiu o curso em 1972. Publicou seis livros: Transposição (1969), Helianto (1973), Alba (1983), Rosácea (1986), Trevo (1988) reunião de seus livros anteriores e Teia (1996). Morreu em 1998.

ABSTRACT :

This text analyzes the poetry of Orides Fontela to discuss the author's personal and unusual approach to silence and death.

KEY WORDS: poetry, silence, nothingness, death.

REFERÊNCIAS BIBLIOGRÁFICAS

BLANCHOT, Maurice. A parte do fogo. Tradução de Ana Maria Scherer. Rio de Janeiro: Rocco, 1997.

CANDid0, Antonio. Prefácio. In: Fontela, Orides. Alba. São Paulo: Roswitha Kempf/Editores, 1983.

CHAUÍ, Marilena. Prefácio. In: Fontela, Orides. Teia. São Paulo: Geração Editorial, 1996.

FONTELA, Orides. Trevo (1969-1989). São Paulo: Duas Cidades, 1988.

- Teia. São Paulo: Geração Editorial, 1996.

- Sobre poesia e filosofia - um depoimento. In:

$\overline{P o e s i a}$ (e) Filosofia. Rio de Janeiro: Sette Letras, 1998.

LISPECTOR, Clarice. Água viva. Rio de Janeiro: Artenova, 1973.

LUCCHESI, Marco. Os céus da poesia. In: Pucheu, Alberto (Org.). Poeisa (e) filosofia. Rio de Janeiro: Sette Letras, 1998.

MERQUIOR, José Guilherme. A astúcia da mímese: ensaios sobre líricas. Rio de Janeiro: José 0lympio, 1972.

SÊNECA, Lúcio Aneu. Sobre a brevidade da vida. Trad., notas e introd. de William Li. São Paulo: Nova Alexandria, 1993. 